\title{
A measurement device for motion analysis of patients with Parkinson's disease using sensor based smart clothes
}

\author{
K.Niazmand *, K. Tonn *, A. Kalaras *, S. Kammermeier †, K. Boetzel †, J.H. Mehrkens •, T.C. Lueth* \\ * Dept. Micro Technology and Medical Device Technology \\ Technische Universität Muenchen Garching, Germany \\ $\dagger$ Dept. of Neurology, $\diamond$ Dept. of Neurosurgery, Ludwig-Maximilian Universität Muenchen, \\ Klinikum Großhadern, Germany
}

\begin{abstract}
Physical examination, interviews with patients and the results of rating scales for movement disturbances are the basis for the assessment of Parkinson's disease (PD). However, subjectivity in the assessment of the symptoms and the short period of observation are disadvantageous. This paper presents the results of a study to assess the feasibility of using accelerometer data, acquired from smart clothes, to estimate the severity of tremor in patients with PD. Algorithms were implemented to estimate the severity of rest and postural tremor of hands from accelerometer data features. The system developed consists of a pullover with eight integrated accelerometers and a computer. The newly developed system for the detection and assessment of tremor was tested with PD patients. System-based estimates were compared with clinical scores derived via visual inspection of video recordings taken while patients performed a series of standardized motor tasks. A quantifiable objective data acquisition by means of a portable wireless system could evaluate the motor disorders better.
\end{abstract}

Keywords - acceleration sensors; Parkinson's disease (PD); tremor; smart clothes.

\section{INTRODUCTION}

The movement disorder primarily described by Dr. James Parkinson is nowadays defined as a syndrome. The most common form is the idiopathic one (Morbus Parkinson or Parkinson's disease). $0.3 \%$ of the population suffer of it. It is a degenerative neurological disorder caused by the loss of brain cells producing dopamine (a neurotransmitter). Lack of dopamine induces the following symptoms: muscle rigidity (an increase in muscle tone causing resistance to passive movement throughout the whole range of movement), tremor (involuntary rhythmic oscillations of one or more body parts), bradykinesia (slowness of movement) and hypokinesia (decreased bodily movement) [1].

For therapy of Parkinson's disease (PD), Levodopa is the medication of the first choice. Levodopa usually has a good effect for the first five to ten years of the treatment.

This work has received funding from the Bavarian Research Foundation (BFS) under contract number AZ-780-07. The views expressed here are those of the authors only. The BFS is not liable for any use that may be made of the information contained therein.
An unwanted side-effect is the Levodopa-induced dyskinesia (LID), which induces movement fluctuations and disorders [1]. In the last stage of PD, the deep brain stimulation (DBS) is an established and effective method to treat therapyrefractory situations or as an alternative to intolerance of the medication.

The choice of drug and its dose depends on the severity of the symptoms. For diagnosis and assessment of movement disorders, the neurologist uses an interview, an examination of motor tasks and a rating scale, like the Unified Parkinson's Disease Rating Scale (UPDRS).

So far, a technical device to objectively assess movement disorders is lacking. A quantifiable, objective and continuous data acquisition could contribute to the improvement of diagnosis and therapy. In particular, in the late stage of PD with decreasing effect of the medication and new disturbances of movement, more information about the disease evolution over a day is important in order to improve the therapy. Furthermore, the data acquisition should occur without any discomfort for both patient and care-giver and should be location-independent.

\section{STATE OF THE ART}

The most commonly used rating scale is the Unified Parkinson's Disease Rating Scale (UPDRS). Motor functions evaluated herein are rest tremor, action tremor, postural tremor, brady- and hypokinesia of the finger-, hand- and arm movements which are estimated during tasks like ,arms stretched out", „finger tapping“ and ,alternating hand movements". Disturbances of gait und postural stability are examined during walking, arising from chair and strong posterior displacement produced by pulling back shoulders of the upstanding patient. UPDRS provides five different levels of severity ranging from 0 to 4 [2]. In research, measurement systems are dynamometers, tachistoscopes, electromyography (EMG) and accelerometers. . In order to assign the symptoms of a category linear discriminate analysis, neuronal networks and support vector machines are used. Specific movement parameters, e.g. reaction time, movement time, amplitude and frequency of acceleration during a movement are used to assess 
quantity and quality of symptoms. In [3] quantitative deviations are described during PD patients are initiating and executing movements. Reaction time (RT) and movement time (MT) were registered by a dynamometer and relationship between these two parameters and the severity of PD symptoms like tremor [4], rigidity [5], akinesia [6] and bradykinesia [7] was investigated. RT and MT were calculated by a computed tachistoscope measurement and bradykinesia, rigidity and tremor were related to RT and MT demonstrating that bradykinesia can be quantified by the movement time [8].

In contrast, tremor cannot be assessed by means of movement time and reaction time [8]. In research electromyography (EMG) and accelerometry can be used for this purpose. EMG measurements are mostly conducted only for a brief time period during a test of rest and postural tremor of the hands [9]. However, short-term recordings of tremor may not reflect the overall disability since the tremor activity exhibits significant fluctuations and diurnal changes. In contrast, movements of body parts can be registered over a longer period of time using accelerometers $[10,11]$. Acceleration sensors were used to detect movement and activity [28]. The kinematical analysis with accelerometers has gained widespread use in medical applications in the last years [12]. Compared to EMG recordings, accelerometry has some practical advantages. EMG recordings usually require preparation of the skin and application of electrodes. In order to develop an assessment method for the tremor activity of PD patients, parameters like frequency, amplitude, and frequency of occurrence of the tremor should be calculated [13, 14]. In [14] the acceleration sensors are fastened with bands to the skin of PD patients. Parameters (amplitude and frequency of movement) are calculated from the dataset of the acceleration values. A tremor is detected if amplitude and frequency of a movement fulfill specific criteria.

To detect dyskinesia, a movement dysfunction in advanced PD, Hoff et al. [15] used linear discriminate analysis, while Keijsers et al. [16] used neuronal networks. In [17] a system is developed, which consists of six sets of three orthogonal accelerometers, a portable data recorder and neuronal networks. The patients performed approximately 35 diurnal activities. They were videotaped to rate the severity of LID on the modified AIMS scale (m-AIMS) off-line by a physician. The m-AIMS rating scale is a five-point scale between 0 (absence of dyskinesia) and 4 (extreme dyskinesia) points [18]. For each body segment, the "segment velocity" was used to compute various variables for each 1-minute interval. These variables and the rating scores were used to train the neural networks.

Ghika et al. [19] and Spieker et al. [20] explore the use of accelerometers and other sensing technology to monitor patients over a longer time. Shyamal Patel et al. [21] leveraged systems to monitor changes of the symptoms of PD and motor complications and developed a classifier (Support Vector Machines, SVM) for tremor, dyskinesia and bradykinesia using acceleration data features. Subjects performed standard motor tasks to evaluate PD patients. Eight uniaxial acceleration sensors were located on the upper and lower limbs of the patients. Acceleration data are recorded and the SVM assesses tremor, bradykinesia and dyskinesia. A comparison of different systems is portrayed in table 1 .
TABLE I. SUMMARY OF THE STATE OF THE ART

\begin{tabular}{|c|l|l|l|}
\hline Ref. & \multicolumn{1}{|c|}{$\begin{array}{c}\text { Measure } \\
\text { System }\end{array}$} & \multicolumn{1}{|c|}{ Parameters } & \multicolumn{1}{c|}{$\begin{array}{c}\text { Classification } \\
\text { Method }\end{array}$} \\
\hline$[3]-[8]$ & $\begin{array}{l}\text { dynamometer } \\
\text { tachistoscope }\end{array}$ & $\begin{array}{l}\text { movement time, } \\
\text { reaction time }\end{array}$ & $\begin{array}{l}\text { linear discriminate } \\
\text { analysis }\end{array}$ \\
\hline$[13]$ & $\begin{array}{l}\text { acceleration } \\
{[14]}\end{array}$ & $\begin{array}{l}\text { amplitude, } \\
\text { fensors }\end{array}$ & $\begin{array}{l}\text { linear discriminate } \\
\text { analysis }\end{array}$ \\
\hline$[16]$ & $\begin{array}{l}\text { acceleration } \\
\text { sensors }\end{array}$ & segment velocity & neuronal network \\
{$[17]$} & acceleration & $\begin{array}{l}\text { Range of amplitude, } \\
\text { cross correlation, } \\
\text { frequency, } \\
\text { signal entropy }\end{array}$ & $\begin{array}{l}\text { support vector } \\
\text { machines }\end{array}$ \\
{$[20]$} & \multicolumn{2}{|l}{} \\
\hline
\end{tabular}

The state of the art for detection and assessment of symptoms of PD are rating scales which are based on physical examinations and interviews by a physician. Rating scales are subjectively affected [27]. The state of research consists of systems, which are composed of different components like wires, video cameras, electronic units to carry, belt-integrated or fastened sensors. The system in [14] can not discriminate tremor from other oscillatory activities. In [17] and [21] the sensors must be fixed by a technician, because an incorrect position can influence the results. These measurement setups are not suited for a time- and place- independent data acquisition and fixed sensors often are uncomfortable for longterm measurements. The development of smart clothes with integrated acceleration sensors and algorithms to detect movement disorders independent of the sensor direction is a challenge. Such a washable measurement device would be comfortable to wear and to put on and records data independent from a laboratory. Patients would move without restriction during measurements.

\section{TASK AND APPROACH}

A device which can assess symptoms of PD in a qualitative and quantitative way would gain a significant improvement in diagnosis and therapy. We developed a system to record movement disorders of PD during execution of standard motor tasks according to Unified Parkinson's Disease Rating Scale (UPDRS).

In [22] we present a novel pullover, which detects falls automatically. The pullover consists of 8 integrated triaxial acceleration sensors and an electronic unit. The tremor usually has a maximum frequency of $7 \mathrm{~Hz}\left(f_{\max }\right)$ [2]. According to the Nyquist's theorem [23], the acceleration values should be sampled with a frequency of minimum $14 \mathrm{~Hz}$. The sensor data in [22] can be recorded with a frequency of $20 \mathrm{~Hz}$. The data can be saved in a SD-card, enclosed in the electronic unit, or it can be sent wirelessly to the basis station. The pullover with the sensors and the electronic unit is washable. On the basis of this system, proper algorithms were developed to allow the assessment of the movement disorders through validated measure values. The assessment based on an objective scale improves the evaluation of movement and therapy.

Moreover, an intuitive operable application was programmed in order to request, achieve and display the sensor data and results. This application should accomplish: 
1. Wireless communication with the pullover

2. Storage of the sensor data

3. Measurement results export

4. Analysis of data as well as a proper statement about assessment of Parkinson's Symptoms.

\section{DELIMITATION:}

Aim of this study was to analyze the feasibility of a universal, non tight-fitting garment containing a measurement system. We recorded the performance of two motor tasks. Further aspects of investigation of movements should follow.

\section{SYSTEM CONCEPT DESCRIPTION}

The developed system (fig. 1) consist of the smart pullover (1) with the eight integrated acceleration sensors (on the right and left upper arm and forearm, on the right and left part of trunk and on the stomach and neck area) (2), a transmit unit (3), a receiver unit (5) and a computer (6). The construction and other details of the smart pullover are described in [22].

Acceleration values are received from the pullover and are saved in a SD-card or sent wireless to a computer. The algorithms for the assessment of Parkinson's symptoms run on the computer, which serves in the processing of acceleration values and giving feedback about the severity of Parkinson's symptoms on the monitor(7).

At the beginning of measurements, the patient puts the pullover on. The user registers the patient data, such as name, age and weight, and chooses the desired symptom for analysis, either rest or postural tremor. The display then shows what the patients should do during the measurement, for example ,arms at rest, , or „arms stretched out“. Sensor data is recorded for $15 \mathrm{~s}$ and an assessment of tremor is calculated, displayed on monitor and stored in the data base. A doctor can request a patient list with the date, time and results of the measurements. The measurement must not be executed by a technician or medical personnel. The program is intuitive operable and selfexplanatory.

\section{A. Determination of relative acceleration}

The acceleration sensors in the pullover collect 3 acceleration values, one for each spatial axis. Because the sensors are not attached in a defined position in relation to the skin surface, the relative acceleration for each sensor is calculated.

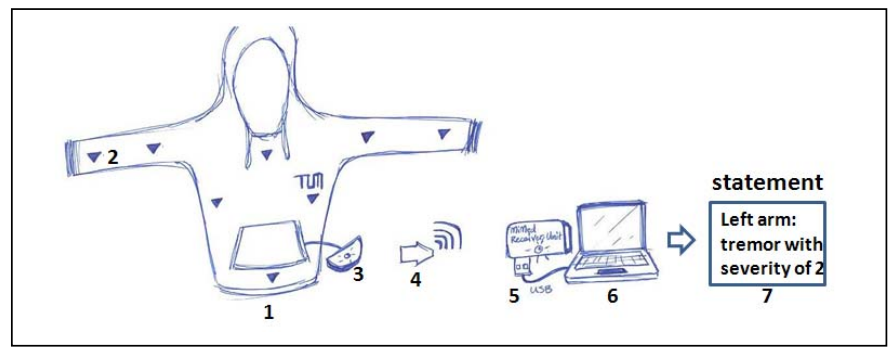

Figure 1.

solution system
The relative acceleration corresponds to the degree of a movement change and is calculated by means of the five following steps:

1) Calculation of the absolute value of the acceleration $(|a|)$ :

Each Sensor in the pullover measures the acceleration in the $\mathrm{x}$ , $y$ - and z-direction. The absolute value of the acceleration is calculated as follows:

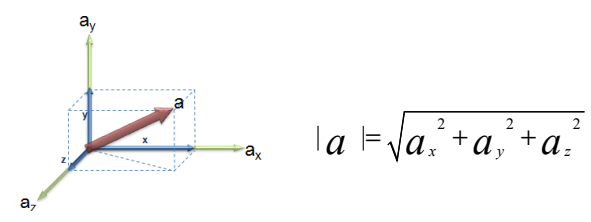

where $a_{x}, a_{y}, a_{z}$ refers to the measured accelerations in $x, y, z-$ direction.

\section{2) Normalization according to Earth's gravity:}

If a sensor is not moved, it measures the acceleration of gravity. During movement, the sensor registers both the acceleration of the sensor and the acceleration of gravity. Therefore, the acceleration of gravity must be subtracted from the absolute value of the measured acceleration (2).

$$
\mathrm{X}=|\mathrm{a}|-\mathrm{g}_{\mathrm{m}}
$$

\section{3) Filtration:}

Furthermore, the absolute values of the acceleration $(\mathrm{X}[\mathrm{k}])$ are filtered. After filtration, the mean value of the last 20 absolute values for a $20 \mathrm{~Hz}$ data acquisition frequency is generated:

$$
X^{\prime}[k]=\frac{1}{20} \sum_{k-1}^{k-20} X[k]
$$

\section{4) Calculation of the relative acceleration (activity value):}

The relative acceleration (activity value) is calculated as following: The filtered values $\left(X^{\prime}[\mathrm{k}]\right.$ ) are subtracted from the corresponding absolute values of the acceleration $(\mathrm{X}[\mathrm{k}])$ as follows:

$$
X[k]^{\prime \prime}=\frac{d X[k]}{d t}=X[k]-X^{\prime}[k]
$$

\section{5) Elimination of noise:}

The system noise is caused by the electronic unit of the pullover (the microcontroller, the sensors, the wires). In order to calculate the maximum value of this noise $\left(\mathrm{N}_{\mathrm{THLD}}\right)$, the following experiment was executed. The pullover was placed for a minute on a table in rest. The 8 sensors in the pullover, which remained still during this minute, were recording acceleration values, which were wirelessly received and saved on a computer. Ideally, the relative acceleration should be zero during the measurement. If the relative acceleration is greater or less than zero, this value is equal to the system noise. 
The relative accelerations were calculated from the received acceleration values through the steps 1 to 4 and were rounded. The frequency of occurrence of system noise from -3 to 3 $( \pm 256= \pm 1 \mathrm{~g})$ for all sensors were summed and depicted in fig. 2.

The result of experiment demonstrates that the maximum absolute value of system noise equates 2 or $0.008 \mathrm{~g}_{\mathrm{m}}\left(\mathrm{N}_{\text {THLD }}=\right.$ 2). During normal walking, the relative acceleration ranges to $1.2 \mathrm{~g}_{\mathrm{m}}(=150$ times greater than the system noise). In the last step, the system noise should be eliminated as follows:

$$
X[k] "=\left\{\frac{X[k]^{\prime \prime}=X[k]^{\prime \prime},\left|X^{\prime \prime}\right|>\mathrm{N}_{\text {тнгD }}}{X^{\prime \prime}=0,\left|X^{\prime \prime}\right| \leq \mathrm{N}_{\text {тнLD }}}\right\}
$$

where $\mathrm{N}_{\text {THLD }}$ refers to the level of noise.

\section{B. Determination of movement frequency}

The tremor is an oscillation of a body part. Therefore, the frequency is an important parameter for its assessment. A usual method of frequency analysis is the Fast Fourier Transformation (FFT). However, this method is adapted for periodic signals, like a sinus signal, and not for sporadic signals, like the tremor signals. A method for the calculation of the frequency based on peak detection of relative acceleration in time domain is presented here: Initially, the relative accelerations of a movement are calculated. The time points of the maximum values of the relative accelerations are detected. Therefore, an upper and a lower threshold (red lines in fig. 3) are calculated. In a signal a peak is detected, if the signal initially passes under the lower threshold, after passes over the upper threshold and finally passes again under the lower level. The maximum, which is achieved during this process, is a signal peak. For the calculation of the upper and lower threshold, the mean value and the standard deviation of the relative accelerations are taken into account, in order to detect all the peaks of the signal, even if the peaks have different dimensions. The upper and lower threshold is calculated as follows:

$$
\begin{aligned}
& \text { upper threshold }=\mu_{+}-\frac{\sigma_{+}}{2} \\
& \text { lower threshold }=\mu_{-}+\frac{\sigma_{-}}{2} \\
& \mu_{ \pm}=\frac{\sum_{i=1}^{n_{ \pm}} X_{i}^{( \pm)}}{n_{ \pm}}
\end{aligned}
$$

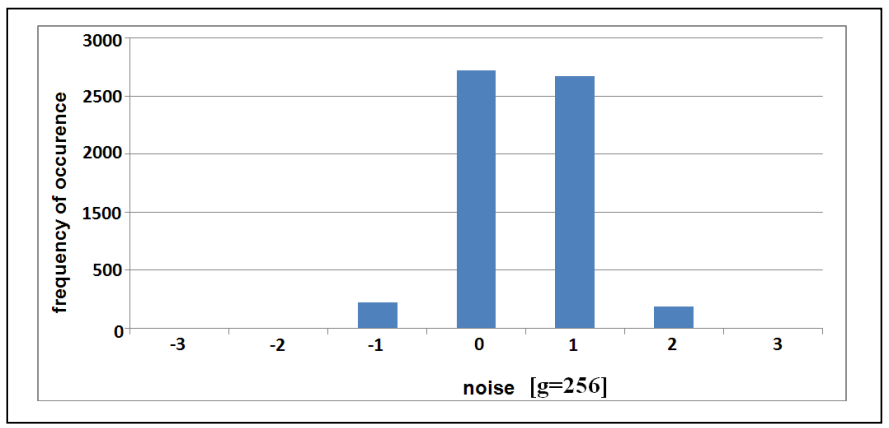

Figure 2. system noise and its frequency of concurrency

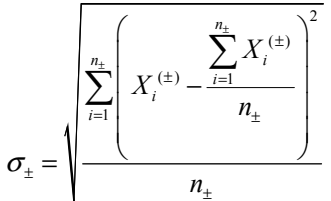

where $X_{i}^{(+)}$and $X_{i}^{(-)}$refers to the $i^{\text {th }}$ positive and negative acceleration and $n_{+}$and $n_{-}$the number of the positive and negative values.

When the time points of the peaks are detected, the distances between these points are calculated $(\Delta \mathrm{T} 1, \Delta \mathrm{T} 2 \ldots)$. The frequency of the signal is calculated as follows:

$$
f=\frac{\frac{1}{\sum \Delta \mathrm{T}}}{\mathrm{N}}
$$

\section{$\Delta \mathrm{T}$ : distance between the points of time of the peaks}

$\mathrm{N}$ : number of the distances

The sensors on the right and left forearm are used for the rest tremor detection, because rest tremor occurs in the area of the hands. In addition four sensors, two sensors on the upper arms and two sensors on the forearms, are used for the detection of postural tremor. The sensors on the upper arms detect, when the patient stretches his arms out and puts his arms down on his thigh. The postural tremor is in the frequency area of the rest tremor, but it can also achieve greater frequencies.

The sampling frequency in the developed system is $20 \mathrm{~Hz}$. Stretch out of arms and put them down should be detected, so that the detection of postural tremor can automatically take part. Sensors are fixed in y-direction parallel to the axe of the upper arm. Thus, the y-acceleration values can be used to detect the raising of the arms.

The range and frequency of the relative acceleration are calculated in order to detect the rest and postural tremor. Both parameters serve as discrimination characteristics between the tremor and the others Parkinson's symptoms, such as Dyskinesia and Hyperkinesia. According to the study of Friedrich Foerster et al. [24] the minimum displacement of the tremor is $0.07 \mathrm{~g}_{\mathrm{m}}$ (ca. $0.7 \mathrm{~mm}$ ) and the maximum displacement is $0.9 \mathrm{~g}_{\mathrm{m}}$ (ca. $9 \mathrm{~mm}$ ).

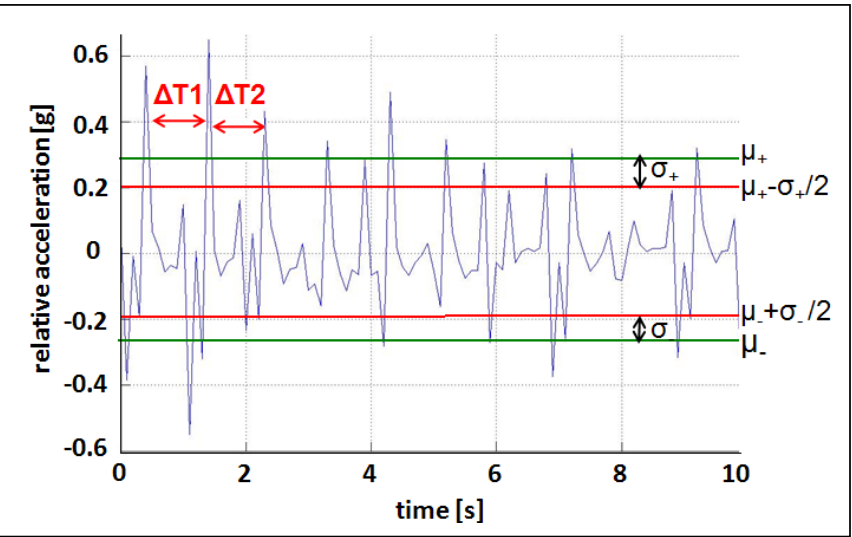

Figure 3.

Calculation of the frequency 
The range of relative acceleration ranges from $0.07 \mathrm{~g}_{\mathrm{m}}$ to 0.9 $\mathrm{g}_{\mathrm{m}}$. Rest tremor or postural tremor can be detect, if the frequency is higher than $0.5 \mathrm{~Hz}$ and the range between $0.07 \mathrm{~g}_{\mathrm{m}}$ and $0.9 \mathrm{~g}_{\mathrm{m}}$ during a measurement. Moreover the assessment of severity of tremor is based on frequency. Measurements were executed on patients with PD in order to find the correspondence between the clinical scores and the frequency ranges. Moreover the assessment of severity of tremor is based on frequency. Acceleration values of movements of PD patients were measured. Movement disorders were videotaped and assessed by a physician using UPDRS, to identify the correspondence between the clinical scores and the frequency ranges. The assessment of tremor according to frequency is shown in table II.

TABLE II. ASSESSMENT OF THE SEVERITY OF TREMOR

\begin{tabular}{|c|c|}
\hline frequency ranges & clinical scores \\
\hline $0-0.50 \mathrm{~Hz}$ & 0 \\
\hline $0.50-0.90 \mathrm{~Hz}$ & 1 \\
\hline $0.90-1.80$ & 2 \\
\hline $1.80-3.40$ & 3 \\
\hline$>3.40$ & 4 \\
\hline
\end{tabular}

\section{Implementation of a PC application}

The method for the detection and assessment of the rest and postural tremor is implemented in a PC application, so that it can be used by medical personnel. The application establishes a wireless communication with the pullover, so that the acceleration values can be analyzed through the algorithms for detection and assessment of the tremor after their receiving at the computer. The acceleration values are saved in database, so that they can be exported as xml-file anytime. A statement about the tremor is displayed on the monitor. The user interface is shown in fig. 4. The results of the measurements are also saved in a data base of the application and are assigned to the patients. Thus, a doctor can request the measurement values and be informed for the changes in the movement disorders of a patient. After a new registration of a patient, a new electronic patient file is added in the data base. The wireless connection to pullover, the battery state and the sensor status are checked.

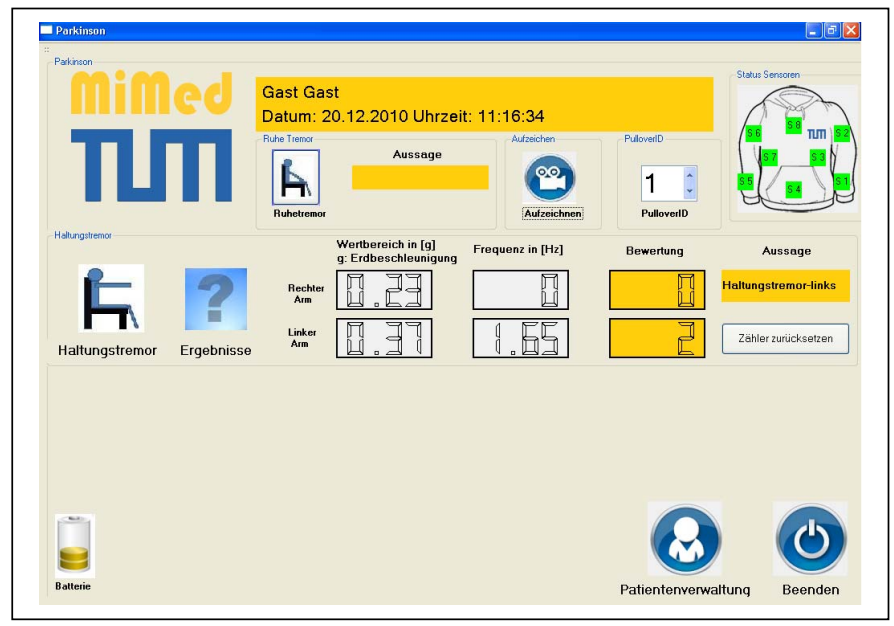

Figure 4.

The application
If the pullover is functioning, a measurement can take place. The user can choose the desired task i.e. rest or postural tremor. During the measurement of the rest tremor, the patient holds his hands at rest on his thigh for $15 \mathrm{~s}$ following the instructions shown, while acceleration values are recorded and analyzed. The measurement of the postural tremor is similar to this of the rest tremor. The system waits until the patient stretches his arms out and after that collects data of the patient for $15 \mathrm{~s}$. Finally, an assessment of the postural tremor is calculated. The schematic flow of this procedure is depicted in fig. 5 .

\section{EVALUATION OF ACCURACY OF LOOSE-FITTING MEASURING PULLOVER}

The measurement of acceleration values with a loose-fitting pullover is not as accurate as the measurement with fixed sensors [26]. It is supposed that the usage of such a measuring system does not affect the assessment of tremor. In respect to this it must be proved whether a loose-fitting pullover records acceleration values as accurately as a tight-fitting pullover or fixed sensors.

\section{A. $\quad$ Set up}

An experiment with two measurements took place in order to investigate the accuracy of the system. In the first measurement the subject (body size suitable for a pullover with size L) puts on eight acceleration sensors fixed on his body extremities and trunk and above the pullover of size $\mathrm{L}$ with the eight integrated sensors.

In the second measurement sensors are fixed on the arms of the subject and he puts on a pullover size XXL. The measured acceleration values were saved in a SD-card. The relative accelerations of the fixed sensors and integrated sensors were calculated.

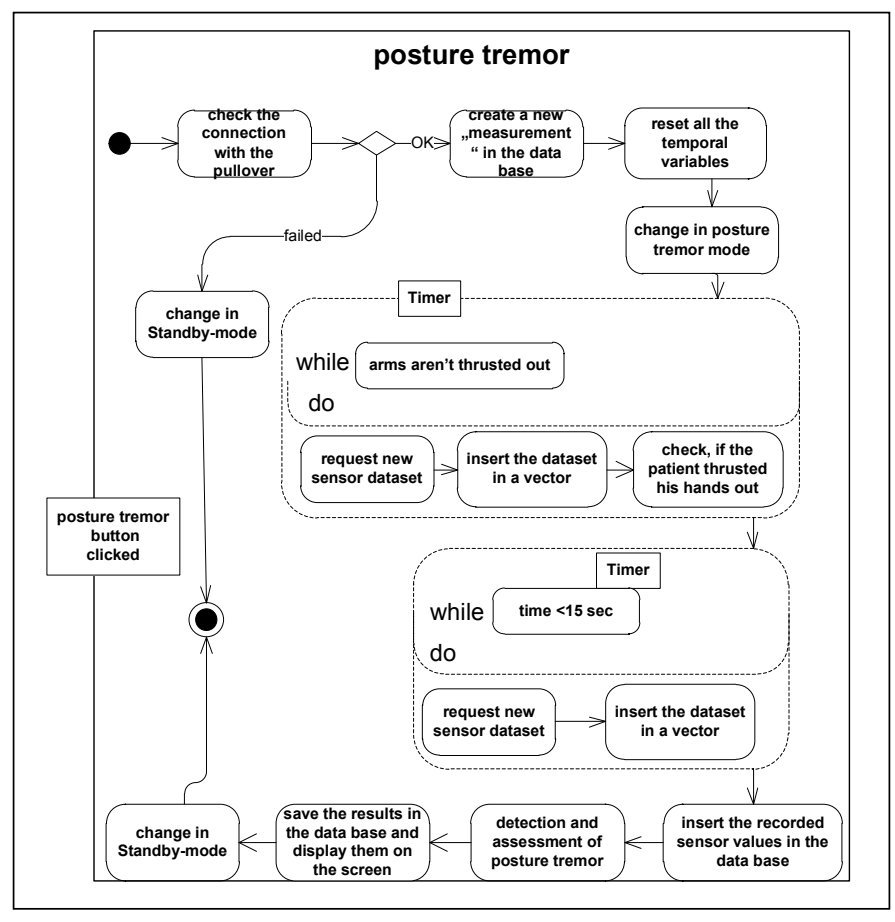

Figure 5. postural tremor mode 
Afterwards the cross correlation of the relative accelerations between the fixed sensors and integrated sensors was calculated through form 10 during different activities. These were going downstairs, stretching out of the arms and simulation of tremor with a low and high frequency. The cross correlation is the maximum normalized value of the vector $\mathrm{c}(\mathrm{m})$.

$c(m)=R_{x y}(m-N)$, where $\mathrm{m}=1, \ldots, 2 * \mathrm{~N}-1$

where: $R_{x y}(m)=\left\{\begin{array}{c}\sum_{n=0}^{N-m-1} x_{n+m} y_{n}^{*}, m \geq 0 \\ R_{y x} *(-m), m<0\end{array}\right\}$

Moreover the assessment of tremor measured by loosefitting and tight-fitting pullover was compared with the assessment of tremor measured by the fixed sensors.

\section{B. Results}

The results (table III) show a high correlation between the fixed and the pullover integrated sensors. The measurement is more precise if the pullover fits exactly to the patients. Absolute value of acceleration and accordingly frequency of tremor differ insignificantly low if they are calculated by fixed sensors and sensors integrated into a tight-fitting pullover. Assessment of tremor was independent of sensor's mounting, fastened or integrated into a loose- or tight-fitting pullover. The assessment is based on the calculated frequency and differs from 0.03 to $0.48 \mathrm{~Hz}$ for sensors in tight-fitting pullover and fixed sensors and from 0.57 to $0.85 \mathrm{~Hz}$ for sensors in loosefitting pullover and fixed sensors. Different assessment of tremor recorded by fixed sensors or integrated sensors may occur, but there is no deviation of assessment more than onepoint in UPDR-Scale.

\section{EVALUATION OF TREMOR ASSESSMENT}

The functionality of the system should be proved by measurements on patients.

\section{A. Set up}

The system for the assessment of tremor consists of the MiMed-pullover, a camera and a stand with a tablet-PC, a power supply and an antenna (fig. 6).

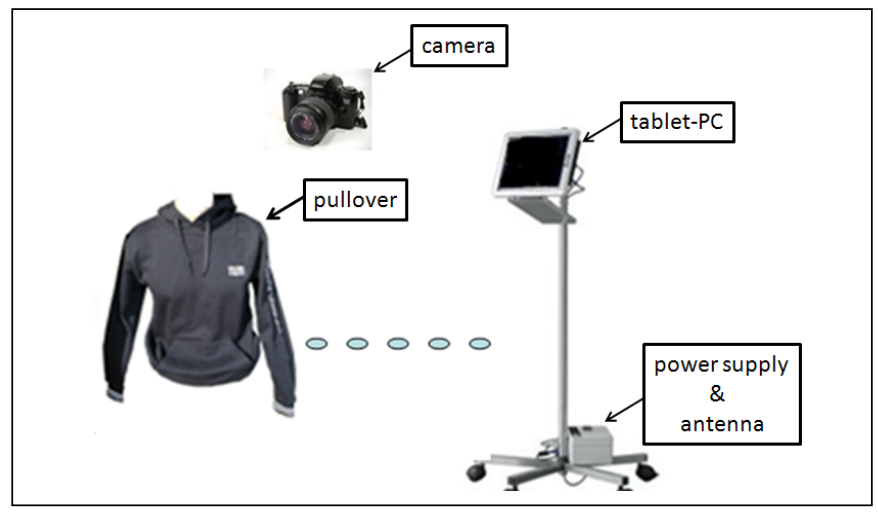

Figure 6.
TABLE III. CORRELATIONS OF THE SENSOR SIGNALS

\begin{tabular}{|l|l|l|l|l|}
\hline \multirow{2}{*}{} & \multicolumn{2}{|c|}{ going downstairs } & \multicolumn{2}{c|}{ thrusting out of the arms } \\
\cline { 2 - 5 } & $\begin{array}{l}\text { pulloverL- } \\
\text { fixed sensors }\end{array}$ & $\begin{array}{l}\text { pulloverXXL- } \\
\text { fixed sensors }\end{array}$ & $\begin{array}{l}\text { pulloverL- } \\
\text { fixed sensors }\end{array}$ & $\begin{array}{l}\text { pulloverXXL- } \\
\text { fixed sensors }\end{array}$ \\
\hline $\begin{array}{l}\text { correlations of the } \\
\text { relative accelerations }\end{array}$ & $85-91 \%$ & $79-82 \%$ & $87 \%$ & $86 \%$ \\
\hline & \multicolumn{2}{|l|}{ simulation of tremor (low frequency) } & \multicolumn{2}{|c|}{ simulation of tremor (high frequency) } \\
\cline { 2 - 5 } & $\begin{array}{l}\text { pulloverL- } \\
\text { fixed sensors }\end{array}$ & $\begin{array}{l}\text { pulloverXXL- } \\
\text { fixed sensors }\end{array}$ & $\begin{array}{l}\text { pulloverL- } \\
\text { fixed sensors }\end{array}$ & $\begin{array}{l}\text { pulloverXXL- } \\
\text { fixed sensors }\end{array}$ \\
\hline $\begin{array}{l}\text { correlations of the } \\
\text { relative accelerations }\end{array}$ & $98 \%$ & $76 \%$ & $89 \%$ & $71 \%$ \\
\hline
\end{tabular}

The sensors of the pullover collect acceleration values and the pullover sends wireless to the tablet-PC, where they are stored and processed by the algorithms described above. Afterwards tremor is classified. For space-time correlation performance of movements is videotaped.

After explaining the referred tasks of UPDRS, volunteers (10 patients with PD, 2 healthy volunteers) put the washed pullover on and measurement started. First, hands and arms were kept at rest, afterwards stretched out, each task for $15 \mathrm{~s}$. The results of the measurements (assessment of the rest tremor and postural tremor, range of the relative acceleration, its frequency) were stored separately for right and left arm. 48 measurements were executed.

Movements were videotaped for later rating by a neurologist to compare the results received by the device and by a neurologist.

\section{B. Results}

At each of the 34 measurements on subjects without rest tremor, the system gave the correct result (fig. 7a). The system detected and assessed rest tremor 10 times during 14 measurements ( $71 \%$ correct results, fig. 7 b). 29 measurements were executed on subjects without postural tremor. The system detected this in all cases (fig. 7c). Furthermore, measurements on subjects with postural tremor were executed 19 times and the system detected and assessed correctly the postural tremor 17 times ( $89 \%$ correct results, fig. 7 d).

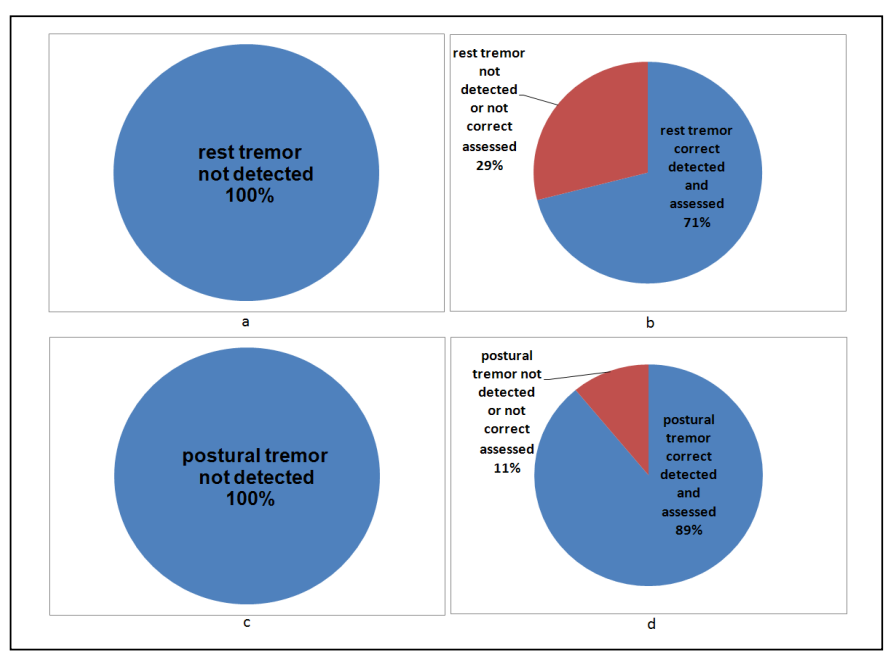

Figure 7. results of the experiments, patient (a) without rest tremor, (b) with rest tremor, (c) without postural tremor and (d) with postural tremor 
Sensitivity, specificity, false positives (FP), false negatives (FN), positive predictive value and negative predictive value of the system in comparison to the physician's evaluation of video recordings of patients are presented in table IV. Detection and correct assessment of the rest tremor took place with sensitivity of $71 \%$, for postural tremor it is $89 \%$. The lower sensitivity of the rest tremor $(71 \%)$ compared to sensitivity of postural tremor $(89 \%)$ could be caused by tensed up hands. The assessments of the system and the neurologist are much the same.

\section{CONCLUSIONS}

The first prototype of a diagnostic system to detect and assess rest tremor and postural tremor of hands and arms in PD patients was presented and tested. This washable measurement system differs from other systems because it is comfortable to wear and to put on and records data independent from a laboratory or technical staff.

Two motor tasks of UPDRS lasting $15 \mathrm{sec}$ were performed by two healthy volunteers and 10 PD patients and recorded by video to be evaluated later by a physician.

The system consists of a pullover with eight integrated accelerometers. The sensor data was sent wirelessly to a computer. A remote computer is used for data analysis, detection, assessment and display of severity of tremor. Results are exported as $\mathrm{xml}$ and txt files. Severity of rest tremor with sensitivity of $71 \%$ and postural tremor of the hand with sensitivity of $89 \%$ is displayed on the monitor.

We demonstrated that movement disorders like tremor can be evaluated quantitatively over a longer period of time without installation of extensive measuring instruments or specialized personnel. For long-term measurements the accuracy of the smart pullover (loose- or tight-fitting) is very important.

The new application of this smart pullover to detect and assess movement disorders collects data largely independent of place and time.

In order to assess further PD symptoms like bradykinesia, hypokinesia or dyskinesia other UPDRS tasks should be implemented. Further measurements under standard conditions with an improved processing algorithm are needed in order to validate the system and to test its reliability. This would improve accuracy of tremor classification. In future works the wireless protocol for the communication between the application and the pullover should be extended to expand the range of mobility. Pullover made of different fabric for correct fit should be designed. Furthermore, the influence of laundry on the accuracy of the system should be investigated.

TABLE IV. RESULTS OF THE EXPERIMENTS

\begin{tabular}{|l|l|l|}
\hline & rest tremor & postural tremor \\
\hline Sensitivity & $71 \%$ & $89 \%$ \\
\hline Specificity & $100 \%$ & $97 \%$ \\
\hline false positive rate & $0 \%$ & $3 \%$ \\
\hline false negative rate & $29 \%$ & $11 \%$ \\
\hline $\begin{array}{l}\text { positive predictive } \\
\text { value }\end{array}$ & $100 \%$ & $94 \%$ \\
\hline $\begin{array}{l}\text { negative predictive } \\
\text { value }\end{array}$ & $89 \%$ & $94 \%$ \\
\hline
\end{tabular}

Sensors integrated into different garments extend the possibility to measure movement disorders. The pants, presented in [25], will be used for gait analysis of PD patients. Gloves with integrated sensors to assess tremor, bradykinesia and rigor will be tested further on in clinical setting, and later on e. g. intraoperatively in Deep Brain Stimulation (DBS) surgery. The stereotactic introduction of the stimulating electrodes is highly dependent on exact assessment of motor responses to test stimulation during the operation.

\section{ACKNOWLEDGMENT}

We acknowledge the assistance of the personnel of the clinic for neurology, LMU Munich. Furthermore, we thank the patients for their support and cooperativeness.

Within the research consortium of the Bavarian Research Foundation (BFS) „FitForAge" a team of scientists and engineers affiliated to 13 departments of the Bavarian universities Erlangen-Nuernberg, Muenchen, Regensburg and Wuerzburg works together with 25 industrial partners on the development of products and services for the aging society.

The scope of the research consortium is to develop technology based solutions which will help elderly people in their future living environment comprising home and workplace as well as in communication and transportation. Eventually not only elderly people but also all social groups should profit from these solutions.

\section{REFERENCES}

[1] Schwarz J., Storch A., "Parkinson-Syndrome“, W. Kohlhammer, p. 1560, 2007.

[2] Schwarz J., Storch A., "Parkinson-Syndrome“, W. Kohlhammer, p. 367379, 2007.

[3] Wilson S., "Disorders of motility and of muscle tone, with special reference to the corpus striatum", Lancet II, pp. 1-10, 1925.

[4] Lichter D., Corbett A., Fitzgibbon G., Davidson O., Hope J., Goddard G., Sharples K., Pollock M., "Cognitive and motor dysfunction in Parkinson's disease”, Arch Neurol. 45, pp. 854-860, 1988.

[5] Ward C., Sanes J., Dambrosia J., Calne D., "Methods for evaluating treatment in Parkinson's disease", Adv. Neurol. 37, pp. 1-7, 1983.

[6] Dubois B., Pillon B., Legault F., Agid Y., Lhermitte F., "Slowing of cognitive processing in progressive supranuclear palsy. A comparison with Parkinson's disease", Arch. Neurol. 45, pp. 1194- 1199, 1988.

[7] Yanagisawa N., Fujimoto S., Tamaru F., "Bradykinesia in Parkinson's disease: disorders of onset and execution of fast movement", Eur. Neurol. 29, pp. 19-28, 1989.

[8] Zappia M., Rita Montesanti, Rosanna Colao and Aldo Quattrone, "Usefulness of movement time in the assessment of Parkinson's disease", Journal of Neurology vol. 241 number 9, pp. 543-550, 1994.

[9] Cleeves L., Findley L., "Variability in amplitude of untreated essential tremor", Journal of Neurology, Neurosurgery and Psychiatry 50, pp. 704-708, 1987.

[10] Van Hilten J., Hoff, J., Roos R., „Ambulatory activity monitoring: An evaluation of day-to-day variability in patients with Parkinson's disease and healthy elderly", Journal of Ambulatory Monitoring, pp. 219-223, 1993.

[11] van Hilten J., Middelkoop H., Kerkhof G., Roos R., "A new approach in the assessment of motor activity in Parkinson's disease", Journal of Neurology, Neurosurgery and Psychiatry vol. 54 issue 11, pp. 976-979, 1991.

[12] Fahrenberg J. Foerster, F. Smeja M., Müller W., “Assessment of posture and motion by multichannel piezoresistive accelerometer recordings", Psychophysiology 34, issue 5, pp. 607-612, 1997. 
[13] Foerster, F., Smeja, M., "Joint amplitude and frequency analysis of tremor activity", Electromyography \& Clinical Neurophysiology, 39(1), pp. 11-19, 1999.

[14] Smeja M., "24-h Assessment of tremor activity and posture in Parkinson's disease by multi-channel accelerometry", Journal of Psychophysiology 13, pp. 245-256, 1999.

[15] Hoff J., van de Plas A., Wagemans E., van Hilten J., "Accelerometric assessment of levodopa-induced dyskinesias in Parkinson's disease", Movement Disorders, vol.16, issue 1, pp. 58-61, 2001.

[16] Keijsers N., Horstink M., van Hilten J., Hoff J., Gielen C., "Detection and assessment of the severity of levodopa induced dyskinesia in patients with Parkinson's disease by neural networks", Movement Disorders, vol.15, issue 6, pp. 1104-1111, 2000.

[17] Keijser N.: “Ambulatory Motor Assessment in Parkinson's Disease", Movement Disorders Vol. 21 Issue 1, pp. 34-44, Januar 2006.

[18] Guy W., "AIMS in ECDEU assessment manual", Rockville, MD: US Department of Health, Education, and Welfare, pp 534-537, 1976.

[19] Ghika J., A. W. Wiegner, J. J. Fang, L. Davies, R. R. Young, and J.H. Growdon, "Portable system for quantifying motor abnormalities in Parkinson's disease," IEEE Trans. Biomed. Eng., vol. 40, no. 3, pp. 276-283, Mar. 1993.

[20] Spieker S., C. Jentgens, A. Boose, and J. Dichgans, "Reliability, specificity and sensitiveity of long-term tremor recordings", Electroencephalograph Clinic Neurophysiology, vol. 97, pp. 326-331, 1995.

[21] Shyamal Patel, Konrad Lorincz, Richard Hughes, Nancy Huggins, John Growdon, David Standaert, Metin Akay, Fellow, Jennifer Dy, Matt Welsh and Paolo Bonato, "Monitoring Motor Fluctuations in Patients With Parkinson's Disease Using Wearable Sensors", IEEE Transactions on information technology biomedizin vol. 13 No. 6, pp.864-873, November 2009.
[22] Niazmand, K.; Jehle, C.; D'Angelo, L.T.; Lueth, T.C.:“ A New Washable Low-Cost Garment for Everyday Fall Detection”, 32nd Annual International IEEE EMBS Conference, 2010.

[23] Hans Marco, „Systemtheorie: Methoden und Anwendungen für einund mehrdimensionale Systeme“", Springer Verlag, pp. 129-130, 1995.

[24] Foerster F., Thielgen T., Fuchs G., Hornig A. und Fahrenberg J., „24stündige Tremor-Untersuchungen an Parkinson-Patienten“, Forschungsberichte des psychologischen Instituts der Alberts Ludwigs Universität Freiburg, Bd. 151, pp.29-31, 2001.

[25] Niazmand, K.; Somlai, I.; Louizi, S. \& Lueth, T.C., "Proof of the accuracy of measuring pants to evaluate the activity of the hip and legs in everyday life", Interna-tional ICST Conference on Wireless Mobile Communication and Healthcare - Mobi-Health, 2010.

[26] Harms, H. ; Amft, O. ; Troster, G.," Influence of a loose-fitting sensing garment on posture recognition in rehabilitation", Biomedical Circuits and Systems Conference IEEE 2008, pp.353-356, 2008

[27] Post B. et al., "Unified Parkinson's Disease Rating Scale Motor Examination: Are Ratings of Nurses, Residents in Neurology and Movement Disorders Specialists Interchangeable?", Movement Disorders, Vol.20, Nr. 12, pp.1577-1584, 2005

[28] D’Angelo, L.T.; Czabke, A.; Somlai, I.; Niazmand, K.; Lueth, T.C.; "ART - a new concept for an activity recorder and transceiver," Engineering in Medicine and Biology Society (EMBC), 2010 Annual International Conference of the IEEE, pp.2123-2135, Aug. 31 2010Sept. 42010 